\title{
Oxide-Assisted Degradation of Ni-Base Single Crystals During Cyclic Loading: the Role of Coatings
}

\author{
Tresa M. Pollock, ${ }^{\dagger, \ddagger \S}$ Britta Laux, ${ }^{\ddagger}$ Clinique L. Brundidge, ${ }^{\S}$ Akane Suzuki, ${ }^{\circledR}$ and Ming Y. He \\ ${ }^{\ddagger}$ Materials Department, University of California, Santa Barbara, CA 93106 \\ ${ }^{\S}$ Department of Materials Science and Engineering, University of Michigan, Ann Arbor, MI 48105 \\ 'GE Global Research, Niskayuna, NY 12309
}

\begin{abstract}
The role of oxidation-induced layers in the failure process of aluminide-coated nickel base single crystals subject to high-temperature fatigue cycling has been investigated experimentally and via finite element analysis. Isothermal strain-controlled compressive fatigue experiments $(R=-\infty)$ with 120 s holds in compression were conducted at $982^{\circ}$ and $1093^{\circ} \mathrm{C}$. Surfaceinitiated cracks containing a layer of alumina progressively grew through the coating layers into the superalloy substrate, ultimately causing failure. Growth stresses in the oxide provided a driving force for extension of the oxide into the softer coating and substrate layers. Finite element modeling shows the rate of growth of the oxide-filled cracks is sensitive to the strength of the constituent layers and the magnitude of the oxide growth strains. Implications for design of failure-resistant coating-substrate systems are discussed.
\end{abstract}

\section{Introduction}

$\mathrm{T}$ URBINE blades are among the most critical components of advanced aircraft engines and power generation turbines and the properties of their constituent materials pose significant constraints to engine performance and efficiency. In the extreme combustion environments of turbine engines the nickel-base single crystal turbine airfoils require coatings for enhancement of oxidation, corrosion, and for extension of maximum temperature capabilities. ${ }^{1-3}$ Coatings, including aluminide and/or yttriastabilized zirconia (YSZ)-based thermal barrier layers often constitute a significant fraction of the airfoil wall thickness ${ }^{1,4}$ and may therefore strongly influence the overall thermomechanical response of the turbine blade. However, to date, coatings have not been designed to enhance the mechanical performance of the system, since the coating-substrate degradation mechanisms under relevant mechanical cycling conditions are not well understood and coating properties are often unknown.

Damage accumulation in turbine airfoils during service is driven by the superposition of centrifugal and vibratory stresses with thermal stresses that arise due to internal air-cooling. ${ }^{5}$ In the absence of a thermal barrier, the impingement of hot gases on the surface of the airfoil and the constraint caused by the cooler inner surfaces typically results in surface compressive stresses. ${ }^{5-7}$ Under these conditions, the failure of nickel-base single crystals subjected to thermomechanical fatigue cycling typically occurs by surface crack initiation and subsequent propagation inward through the coating into the substrate. ${ }^{6}$ This damage growth process is influenced by the simultaneous oxi-

C. Levi-contributing editor

\footnotetext{
Manuscript No. 29073. Received December 21, 2010; approved March 19, 2011.

This work was supported by the ONR Grant N00014-08-1-0331.

Author to whom correspondence should be addressed. e-mail: pollock@engineering. ucsb.edu
}

dation of the intermetallic coating and/or the superalloy substrate. $^{6-17}$ When a thermal barrier coating (TBC) is present, these processes often occur following local spallation of the YSZ, resulting in "conservative" maximum design temperatures being imposed on the TBC. Material degradation is further accelerated by sustained compressive holds present in the fatigue cycle. ${ }^{6,14}$ Herein fatigue cycling with holds will be referred to as sustained peak low cycle fatigue (SPLCF). During the compressive hold, creep deformation occurs, resulting in tension upon returning to zero strain at the end of the cycle, Fig. 1. Cracks, if present, then open at the end of the cycle, permitting oxidation along the crack faces and at the crack tip. As degradation due to SPLCF cycling often limits the performance of aircraft and power generation turbines, ${ }^{6}$ a better understanding of the mechanics and materials issues resulting in SPLCF failure is needed to motivate development of more optimal substrate-coating combinations.

Evans and colleagues ${ }^{7,18}$ recently proposed a model for oxideassisted crack growth during SPLCF cycling. The model is unique in that it embodies the same mechanics and phenomena previously used to successfully predict rumpling of the thermally grown oxide (TGO) on bond coats ${ }^{19-24}$ in the absence of fatigue cycling. In the model, alumina forms on the superalloy sample surface as well as on the faces of incipient cracks. The early stages of this process on the surface of a Ni-base single crystal sample are shown in Fig. 2, where an incipient crack filled with oxide is penetrating into the superalloy substrate.

During continued oxidation in these high-temperature systems, while most of the new $\alpha-\mathrm{Al}_{2} \mathrm{O}_{3}$ forms at the surface by inward diffusion of oxygen, an outward counter-flux of $\mathrm{Al}$ causes some new oxide to form along the transverse grain boundaries. ${ }^{19,20}$ The alumina formed on the grain boundaries is accommodated by lateral straining of the neighboring grains, at a strain-rate $\dot{\varepsilon}_{\text {growth }} \cdot{ }^{22-24}$ The oxide responds by creeping and a steady state a compressive growth stress, $\sigma_{\text {growth }}$ is quickly established, wherein creep relaxation balances the stresses caused by the growing oxide. ${ }^{25,26}$ The magnitude of this stress has been measured in situ for the TGO on several different bond coats and is of order $\sigma_{\text {growth }} \approx-300 \mathrm{MPa},{ }^{25,26}$ consistent with deformation mechanisms for $\alpha-\mathrm{Al}_{2} \mathrm{O}_{3}$ and with stress relaxation rates measured in a typical TGO. ${ }^{27}$ When the surface is nonplanar, Fig. 2, the stress $\sigma_{\text {growth }}$ exerts a downward pressure on the softer substrate, causing it to creep, ${ }^{7,16,22,27}$ resulting in the development of crack-like features. Continued growth of the oxide as the crack opens in tension upon returning to zero strain, Fig. 1, and deformation of the oxide and substrate during the compressive fatigue loading portion of the cycle result in a continued penetration of the oxide-filled crack deep into the substrate to the point where the crack becomes physically long and begins to grow in a manner consistent with that observed in conventional cyclic crack growth experiments. ${ }^{7,12}$ In this paper, the oxide-assisted damage growth model is further developed for analysis of the key features of the superalloy-coating system 

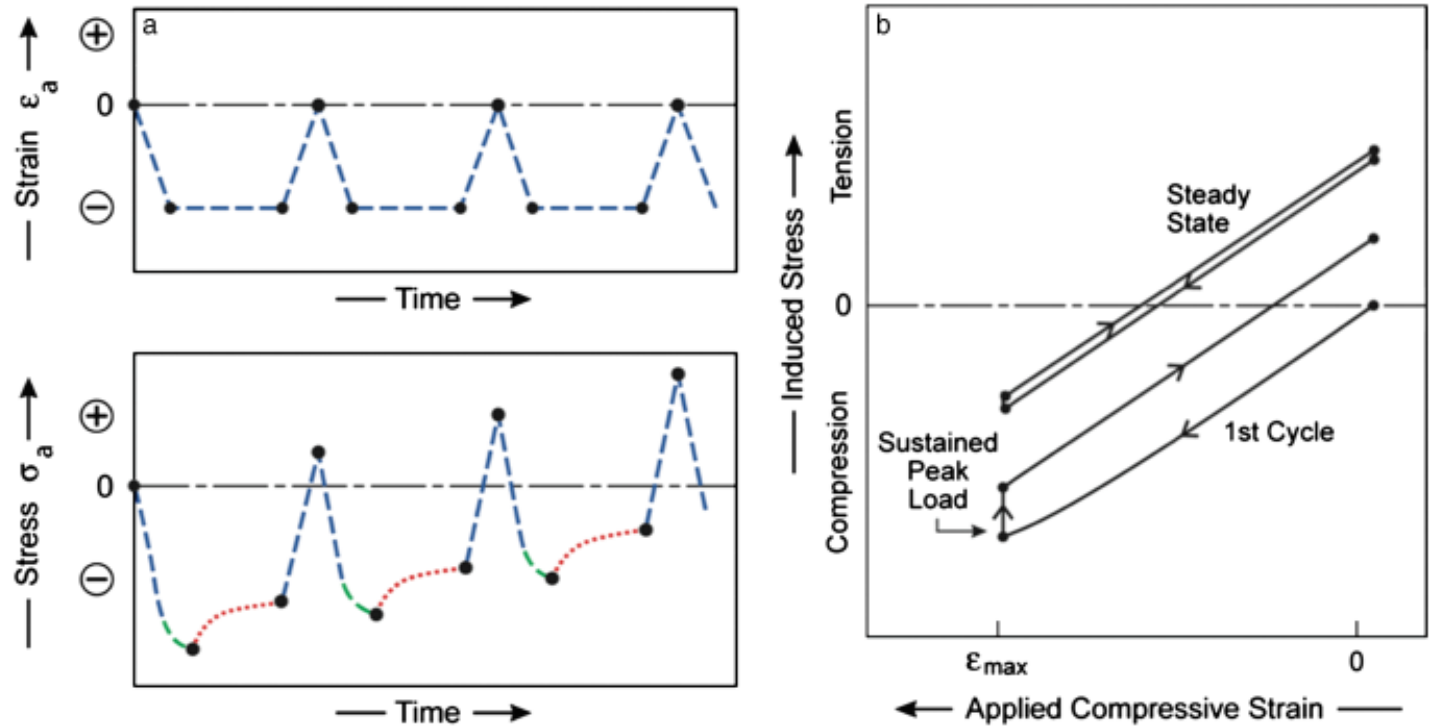

Fig. 1. Schematics of the applied straining conditions associated with sustained peak load cyclic fatigue. (a) The compressive strains imposed and trends in the stresses induced as cycling proceeds. (b) The stress/strain loops and their evolution with cycling.

that influence the rate of damage development. The SPLCF degradation process is considered for the intermetallic coating, the interdiffusion zone and the superalloy substrate (without the presence of a thermal barrier). Corresponding SPLCF experiments are also presented for uncoated and coated variants of René N5 superalloy single crystal.

\section{Experimental Approach}

To study crack advance mechanisms, experimental thermomechanical cycling experiments have been conducted on single crystal substrates of René N5 with a nominal composition of $7.5 \mathrm{Co}-7.0 \mathrm{Cr}-1.5 \mathrm{Mo}-5.0 \mathrm{~W}-6.5 \mathrm{Ta}-6.2 \mathrm{Al}-3.0 \mathrm{Re}-0.15 \mathrm{Hf}-\mathrm{Bal} \mathrm{Ni}$ (wt \%). Tests were conducted on bare, uncoated crystals, and on samples coated with either a standard $\mathrm{Pt}$ aluminide $(\mathrm{PtAl})$ or a vapor phase (Pt-free) nickel aluminide (VPA) coating. ${ }^{28}$ Coatings were applied directly to [001] single crystal fatigue samples with $5 \mathrm{~mm}$ gage diameter and $19 \mathrm{~mm}$ gage length. The initial thickness of the $\beta$-NiAl layer in the coating was approximately $50 \mu \mathrm{m}$. Since the coating structure develops by diffusion, an interdiffusion layer of comparable thickness to the $\beta$-layer is also formed as a part of the process. A summary of sample testing conditions is given in Table I.

High-temperature SPLCF cycling experiments were conducted isothermally in air at an $R$-ratio of $R=-\infty(A=-1.0)$ with

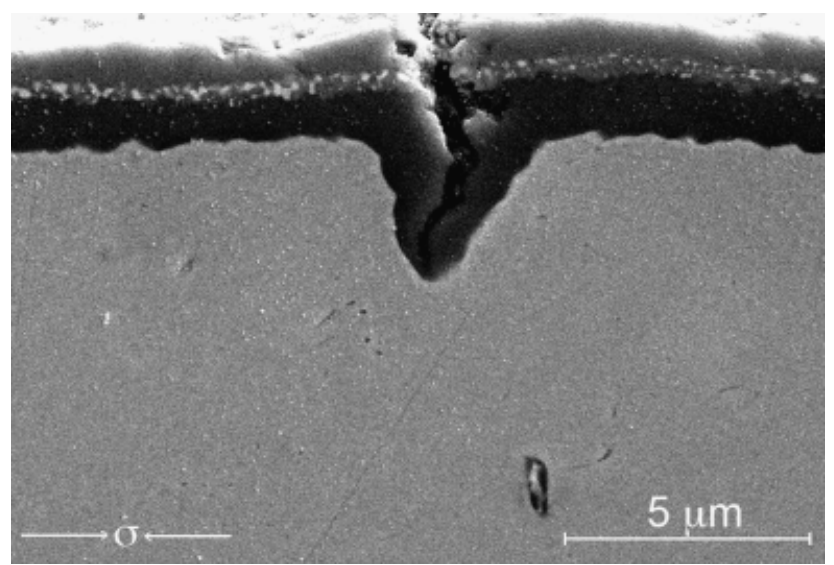

Fig. 2. Cracks in the surface oxide extending into the Ni-base superalloy during fatigue cycling with compressive holds at $1093^{\circ} \mathrm{C}$. 120-s compressive holds combined with a 3-s loading-unloading cycle, Fig. 1 . Tests were conducted at $982^{\circ}$ and $1093^{\circ} \mathrm{C}$ with total strain ranges varying from $0.20 \%$ to $0.96 \%$. Cycling was conducted in a standard servohydraulic system in strain-controlled mode and hysteresis loops were analyzed. Following cycling, cracking on the surfaces of samples was characterized by optical and scanning electron microscopy. Samples were then sectioned longitudinally for analysis of crack depths and the development of the oxide on the surface and within the cracks.

\section{Experimental Results}

At $1093^{\circ} \mathrm{C}$ the majority of the experiments were conducted at a constant total strain range of $\Delta \varepsilon_{\mathrm{t}}=0.35 \%$. Experimentally measured hysteresis loops for an uncoated sample with a total number of cycles to failure of $N_{\mathrm{f}}=6755$ cycles are shown in Fig. 3. In the first cycle, the sample is compressively loaded and held at point " $\mathrm{A}$ " for $120 \mathrm{~s}$. During the 120-s hold, creep deformation causes a reduction in the stress from about -240 to $-160 \mathrm{MPa}$. Upon returning to zero strain, the sample experiences a tensile

Table I. Experimental SPLCF Testing Conditions

\begin{tabular}{lcccr}
\hline Sample \# & Coating & Temperature $\left({ }^{\circ} \mathrm{C}\right)$ & Total strain range $(\%)$ & \# Cycles $^{\dagger}$ \\
\hline 1 & PtAl & 982 & 0.94 & 801 \\
2 & PtAl & 982 & 0.88 & 1260 \\
3 & PtAl & 982 & 0.77 & 1544 \\
4 & PtAl & 982 & 0.72 & 2234 \\
5 & PtAl & 982 & 0.65 & 3409 \\
6 & PtAl & 982 & 0.60 & 4051 \\
7 & PtAl & 982 & 0.56 & 6483 \\
8 & PtAl & 982 & 0.56 & 6534 \\
9 & VPA & 1093 & 0.35 & $2000^{\dagger}$ \\
10 & VPA & 1093 & 0.35 & $4000^{\dagger}$ \\
11 & VPA & 1093 & 0.35 & $6000^{\dagger}$ \\
12 & VPA & 1093 & 0.35 & $8000^{\dagger}$ \\
13 & VPA & 1093 & 0.35 & 10200 \\
14 & Bare & 1093 & 0.35 & $1000^{\dagger}$ \\
15 & Bare & 1093 & 0.35 & $2000^{\dagger}$ \\
16 & Bare & 1093 & 0.35 & $4000^{\dagger}$ \\
17 & Bare & 1093 & 0.35 & $6000^{\dagger}$ \\
18 & Bare & 1093 & 0.35 & $8000^{\dagger}$ \\
19 & Bare & 1093 & 0.35 & 6755 \\
\hline
\end{tabular}

\footnotetext{
Interrupted tests.
} 


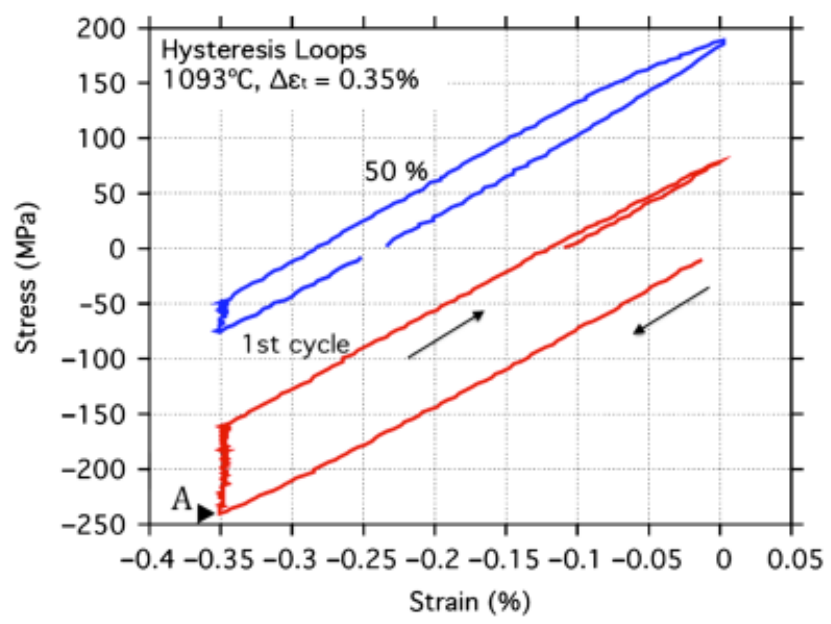

Fig. 3. Hysteresis loops for bare René N5 at start of cycling and at $50 \%$ of total SPLCF life.

stress approximately equal to the magnitude of the stress relaxation. The tensile stresses at the end of the cycle continue to increase until approximately $20 \%$ of the total life, where they stabilize. At $50 \%$ of life for $\Delta \varepsilon_{\mathrm{t}}=0.35 \%$ at $1093^{\circ} \mathrm{C}$, a maximum tensile stress of approximately $190 \mathrm{MPa}$ is reached upon returning to zero strain, Fig. 3. Hysteresis loops are similar for the vapor phase aluminide-coated sample, however, the total cycles to failure increased to $N_{\mathrm{f}}=10200$. Thus the rate of damage accumulation is apparently higher in the uncoated sample.

The dependence of SPLCF life on total strain range for Ptaluminide-coated samples at $982^{\circ} \mathrm{C}$ is shown in Fig. 4. The SPLCF life increases by a factor of approximately $10 \times$ as the strain range is reduced from $0.96 \%$ to $0.56 \%$. Under the conditions studied, the compressive hold can degrade the fatigue life (with no compressive hold) by a factor of up to $100 \times$, depending on the temperature and strain range.

SPLCF cycling of samples to failure as well as experiments interrupted at various fractions of the average failure life have been conducted at $1093^{\circ}$ and $982^{\circ} \mathrm{C}$. At $1093^{\circ} \mathrm{C}$ a series of bare and vapor phase aluminide-coated samples were interrupted at various fractions of total fatigue life. Vapor phase aluminidecoated samples were removed from SPLCF tests after 2000, 4000,6000 , and 8000 cycles (approximately 20\%, 40\%, 60\% and $80 \%$ of life, respectively) at $1093^{\circ} \mathrm{C}$ and $\Delta \varepsilon_{\mathrm{t}}=0.35 \%$ and sectioned longitudinally. While the details of these sectioning studies have been reported elsewhere, ${ }^{6}$ it was observed that cracks do not penetrate beyond the interdiffusion zone until

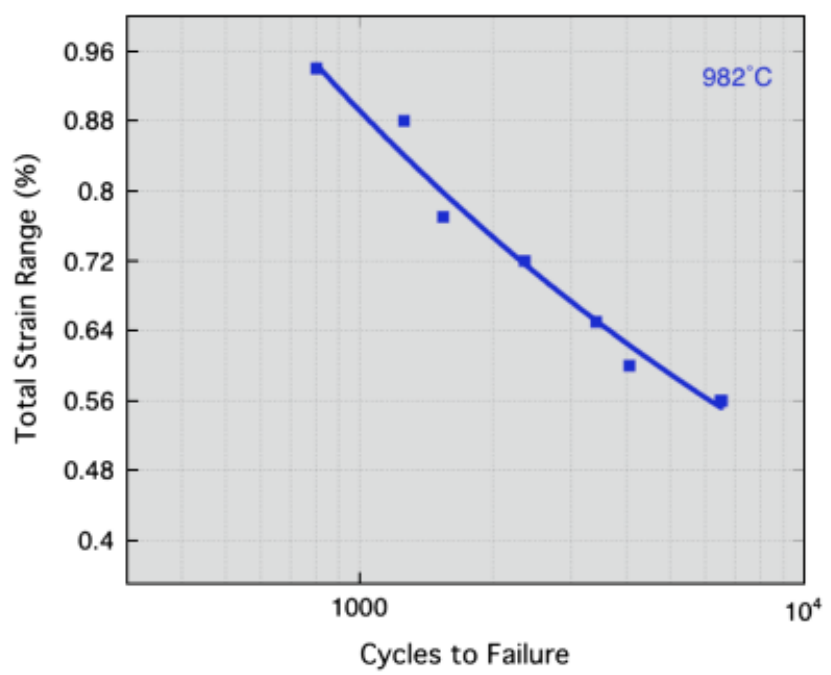

Fig. 4. SPLCF failure data for Pt-aluminide coated René $\mathrm{N} 5$ at $982^{\circ} \mathrm{C}$ cycled with 120 -s compressive holds. approximately $80 \%$ of the life is consumed by cycling. Similarly, testing of a $\mathrm{Pt}$ aluminide-coated sample at $982^{\circ} \mathrm{C}$ with $\Delta \varepsilon_{\mathrm{t}}=0.56 \%$ demonstrates that at failure many cracks have not progressed beyond the interdiffusion zone, Fig. 5. Among the 75 cracks examined along the length of the gage section after failure, only three cracks extended to depths of 150-250 $\mu \mathrm{m}$, not including the one longer crack that ultimately caused failure of the sample, Fig. 5.

The experiments at two temperatures $\left(982^{\circ}\right.$ and $\left.1093^{\circ} \mathrm{C}\right)$ with two different coatings ( $\mathrm{Pt}$ aluminide and vapor phase aluminide) collectively reveal four successive stages of the failure process (Figs. 6 and 7): crack extension from the surface through the (I) bond coat (BC), (II) interdiffusion zone (IDZ), (III) superalloy substrate, and (IV) long crack growth. In the early stages of cycling, many cracks form in the bond coat along the length of the gage section. These cracks gradually progress through the bond coat and interdiffusion zone and into the superalloy substrate. The cracks are filled with an alumina layer a few micrometers thick, Fig. 8, that is relatively uniform in structure and thickness along the surface of the crack. After growth into the superalloy to a depth of a few hundred micrometers, Stage IV is approached and the cracks grow at an inclined angle with respect to the axis of the applied compressive stress, Fig. 7. In many cases coarse striations are visible on the fracture surface in Stage IV, indicating that rapid mixed-mode crack growth occurs in this final stage.

To experimentally assess the role of coatings, interrupted SPLCF cycling tests were also conducted on bare René N5 samples. SPLCF experiments were interrupted at 1000, 2000, 4000,6000 , and 8000 cycles at $1093^{\circ} \mathrm{C}$ with $\Delta \varepsilon_{\mathrm{t}}=0.35 \%$. The average and maximum crack depths are given in Table II. Similar to the coated samples, the cracks do not extend to depths beyond $100 \mu \mathrm{m}$ until very late in life.

\section{Finite Element Modeling of the SPLCF Process}

A series of ABAQUS-based finite element models were developed to elucidate the properties of the substrate, interdiffusion zone, $\beta$-coating and oxide layer that most strongly influence the failure process. The details of a finite element mesh that contains an oxide layer of thickness $h$ on the superalloy surface and within a shallow crack of depth $a$ are shown in Fig. 9. Initial analyses of the crack growth process for an oxide penetrating into the superalloy in this configuration have been presented elsewhere. ${ }^{7}$ These analyses are extended here to consider coatings and the conditions under which damage development is strongly affected by their presence. To study the role of the $\beta$ coating and interdiffusion zone, additional meshes were developed with oxide-containing cracks within the successive layers, as shown schematically in Fig. 10.

High-temperature properties of the substrate have been measured $^{29}$ and these are considered in the model. Two versions of the model have previously been developed ${ }^{7}$ for the oxide on the superalloy: one where creep properties are explicitly considered and a second where an equivalent plasticity analysis is implemented for numerical efficiency. Steady-state creep can be adequately represented by power law behavior of the form: $\dot{\varepsilon}=\dot{\varepsilon}_{\mathrm{o}}\left(\frac{\sigma}{\sigma_{\mathrm{o}}}\right)^{n}$, where $\sigma$ is the local Mises stress, $\sigma_{\mathrm{o}}$ is a reference stress, $\dot{\varepsilon}_{\mathrm{o}}$ a reference strain rate, and $n$ the creep exponent. In the present calculations $\sigma_{\mathrm{o}}=100 \mathrm{MPa}$ and $n=10$. The high-temperature properties of the Pt aluminide bond coat measured in samples removed directly from coatings have been incorporated into the model. ${ }^{30}$ While the properties of the interdiffusion zone have not been directly measured, the properties of alloys with compositions similar to those observed in the interdiffusion zone indicate that the creep rates are likely to be intermediate to those of the weak $\beta$-coating and the precipitation-strengthened superalloy. ${ }^{31}$ To capture the lateral straining in the TGO, in the model, $\dot{\varepsilon}_{\text {growth }}$ is imposed during those stages of the strain cycle when the crack is open. It is imposed at a uniform rate governed by the TGO thickness, $h$. This strain-rate causes creep of the 


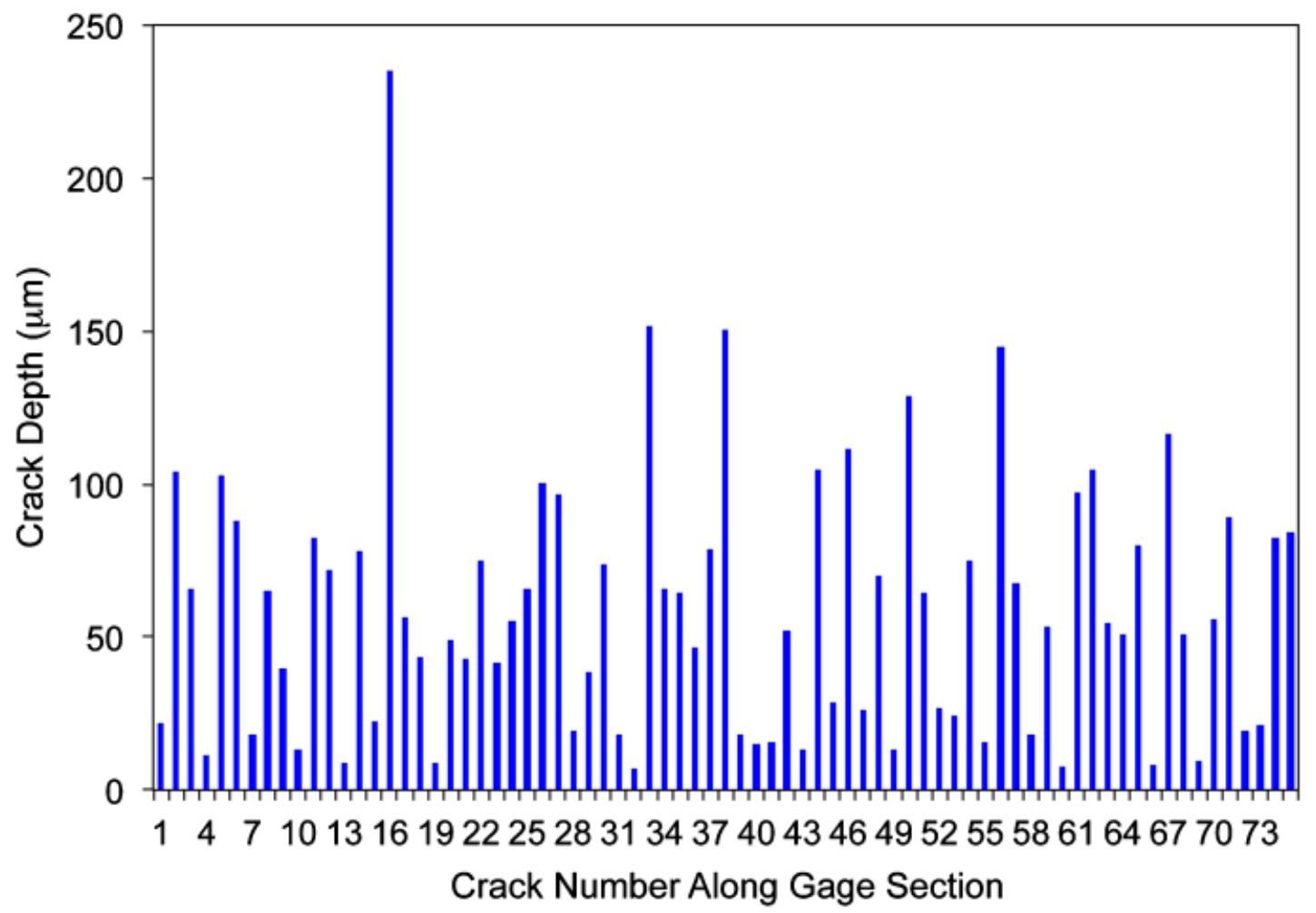

Fig. 5. Crack lengths along the gage section at failure following cycling of a Pt aluminide-coated sample at $982^{\circ} \mathrm{C}$ at $\Delta \varepsilon_{\mathrm{t}}=0.56 \%$.

$\mathrm{TGO},{ }^{27}$ replicated by ensuring that the Mises stress does not exceed the growth stress, $\sigma_{\text {eq }} \leq \sigma_{\text {growth. }}$. The ensuing response of the TGO is governed by the creep deformation of the surrounding material (bond coat, IDZ, or substrate). Namely, creep deformation occurring around the tip accommodates elongation of the TGO along the " $y$ " direction (Fig. 9), leading to a crack extension per cycle. The five parameters affecting the fatigue crack growth rate are thus: the TGO growth stress, $\sigma_{\text {growth }}$, the lateral strain-rate experienced by the TGO as it grows, $\dot{\varepsilon}_{\text {growth }}$, the oxide thickness, $h$, the creep characteristics of the surrounding material, $\dot{\varepsilon}_{\text {sub }}=\dot{\varepsilon}_{o}\left(\frac{\sigma}{\sigma_{o}}\right)^{n}$, and the crack length, $a$. The oxide thickness was assumed to be $h=3 \mu \mathrm{m}$ in all analyses presented here.

The principal features of the damage growth process can also be elucidated by using a plasticity model for the substrate and bond coat (with power law hardening) and by invoking the reference stress method to convert to power law creep. ${ }^{7,18}$ Results presented here are primarily from plasticity analyses. The sequential stages of damage development are considered for bare and coated materials and the conditions where the degradation is dominated by the superalloy, bond coat, and IDZ properties, respectively, are highlighted.

\section{(1) Superalloy Dominated Growth}

Initial calculations considered damage growth for a TGO formed on bare superalloy, to establish a baseline, since the properties of the substrate are well established. Figure 11 considers the early stages of the TGO penetration $\left(a_{\mathrm{o}}=20 \mu \mathrm{m}\right)$ into the superalloy substrate as a function of the strength of the substrate. For a moderate applied compressive strain of $0.4 \%$ and a superalloy strength of $100 \mathrm{MPa}$ (comparable to René N5 at $1093^{\circ} \mathrm{C}$ ) the oxide elongates at a rate of approximately $6.8 \mathrm{~nm} /$ cycle, Fig. 11(b). Across the range of conditions examined, the TGO penetration rate scaled linearly with the oxide thickness, so penetration rates are normalized by the oxide thickness, Fig. 11(a). As the strength of the superalloy approaches approximately $2 / 3$ that of the TGO, the resistance to deformation along

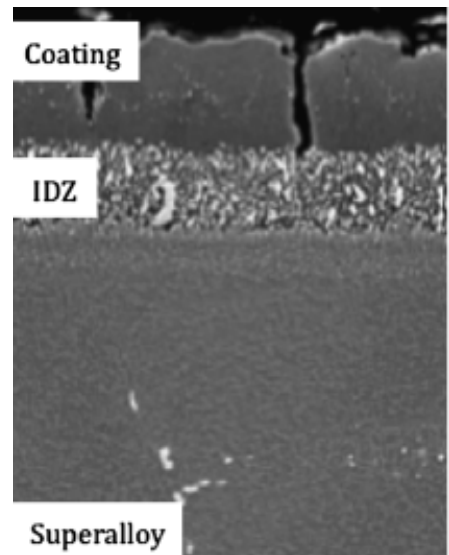

Stage I

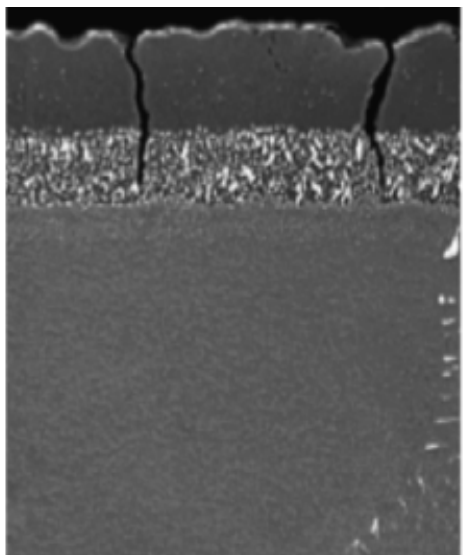

Stage II

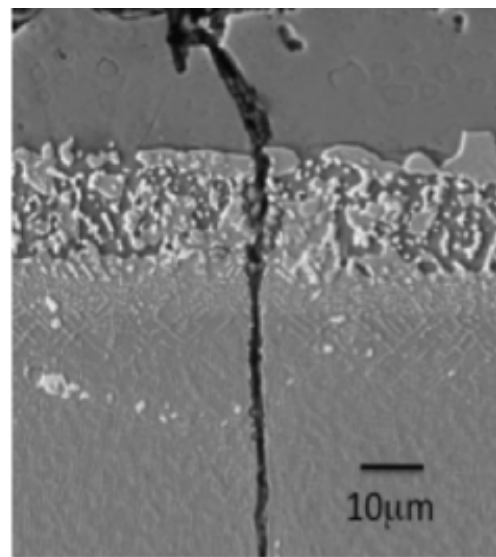

Stage III

Fig. 6. The first three stages of crack progression with cracking in the Pt aluminide bond coat (Stage I), interdiffusion zone (Stage II), and superalloy substrate (Stage III). René N5 tested at $982^{\circ} \mathrm{C}$. 

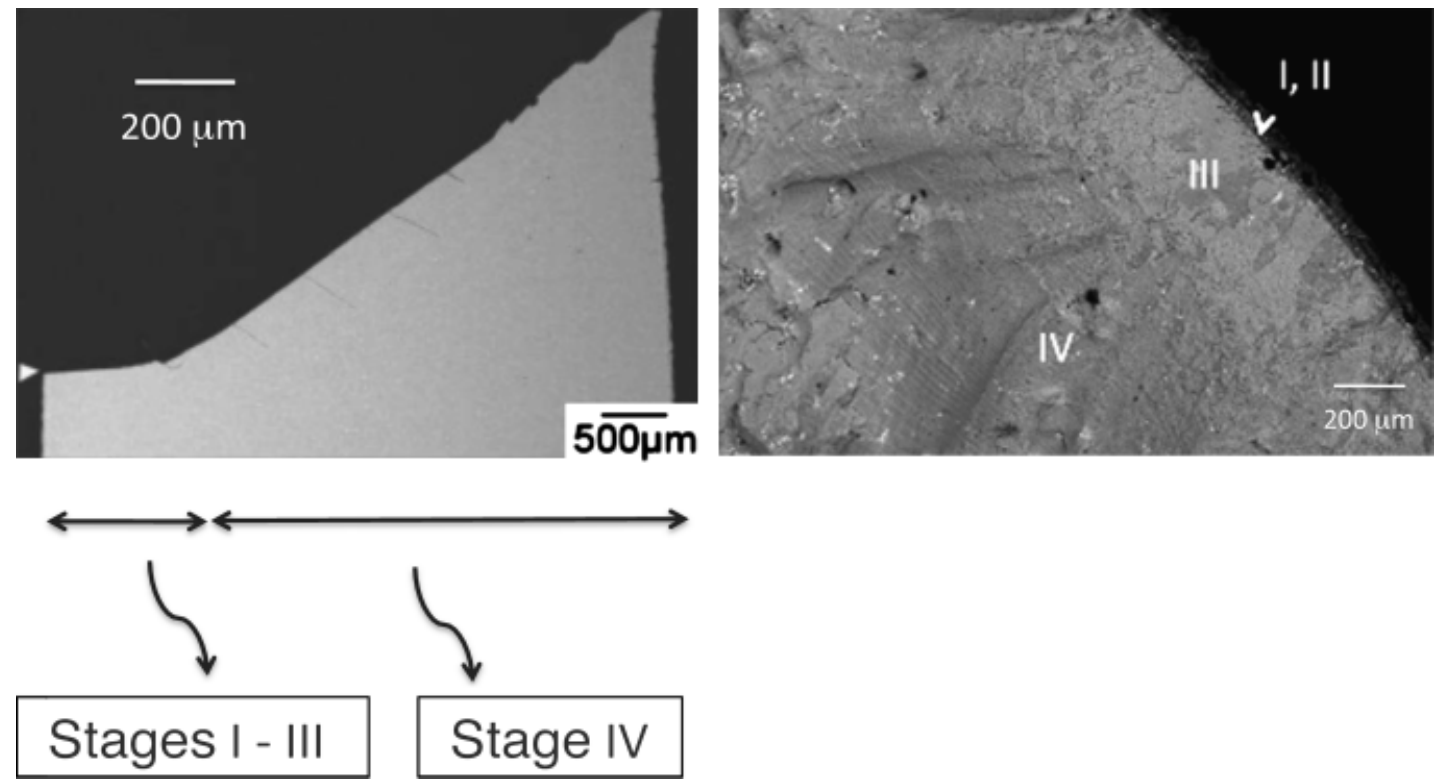

Fig. 7. Longitudinal section through an SPLCF sample showing the four stages of failure, with an inclined crack causing final failure in Stage IV.

SE

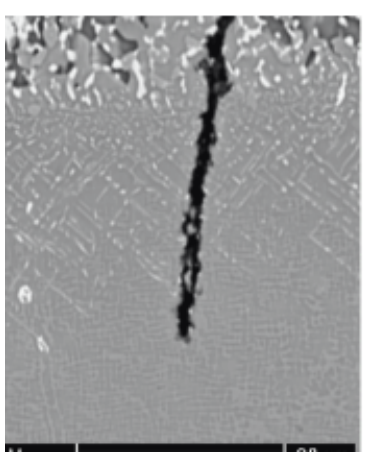

Al

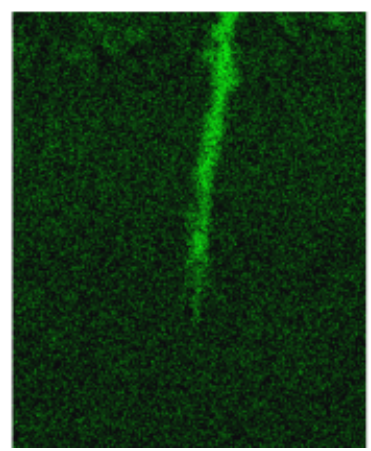

$\mathrm{O}$

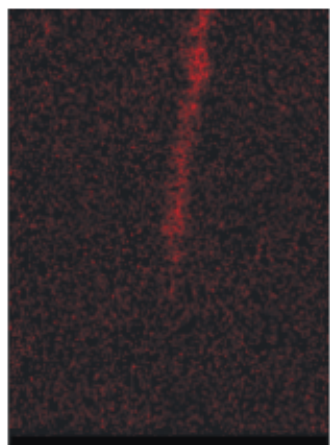

$\mathrm{Ni}$

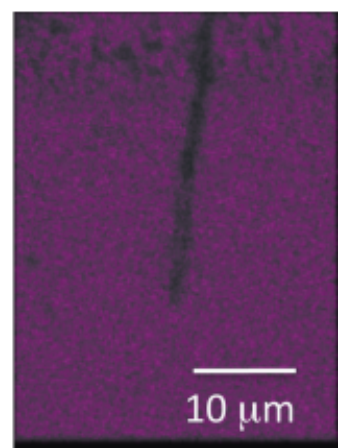

Fig. 8. SEM secondary electron (SE) image and corresponding X-ray maps showing alumina in the crack tip after SPLCF testing of René N5 with Pt aluminide coating at $982^{\circ} \mathrm{C}$.

the surface of the oxide-lined crack face and at the crack tip rises to a sufficiently high level to almost completely suppress crack growth. For an applied compressive strain of $0.35 \%$ and a substrate strength of $100 \mathrm{MPa}$, the TGO penetration rate is $6 \mathrm{~nm} /$ cycle, Fig. 11(a) and rises to $12 \mathrm{~nm} /$ cycle for $50 \mathrm{MPa}$ strength. Experimentally, for an applied compressive strain of $0.35 \%$, uncoated René N5 samples were interrupted after 2000 and 4000 cycles, Table I. The maximum crack depth was measured as $36 \mu \mathrm{m}$ at 2000 cycles and $19 \mu \mathrm{m}$ at 4000 cycles (two distinct samples), corresponding to a crack growth rates in the range of $5 \mathrm{~nm} /$ cycle-18 nm/cycle, in good agreement with the model. A limited number of high-temperature, in-situ experimental investigations on growth strains in the TGO formed on aluminide coatings have been conducted in the temperature range of

Table II. Crack Length Data for Bare René N5 Sample Cycled at $1093{ }^{\circ} \mathrm{C}$ with $\Delta \varepsilon_{t}=0.35 \%$

\begin{tabular}{ccc}
\hline Cycles & Average depth $(\mu \mathrm{m})$ & Maximum depth $(\mu \mathrm{m})$ \\
\hline 1000 & 4.1 & 21.2 \\
2000 & 3.8 & 36.0 \\
4000 & 4.1 & 19.0 \\
6000 & 7.2 & 49.7 \\
6755 & 5.9 & 36.7 \\
8000 & 7.3 & 209.7 \\
\hline
\end{tabular}

$1000^{\circ}-1100^{\circ} \mathrm{C},{ }^{26,32}$ however, no measurements of growth strains are available for the TGO on superalloys. Bond coats experience compressive growth strains varying from $-0.01 \%$ to $-0.10 \%$, so growth strains over this range were used in the modeling for both the bond coat and the superalloy. Figure 12 shows the influence of oxide growth strains on the rate of penetration of the TGO into the substrate. With no growth strains in the oxide, there is still a tendency for the oxide to push into the substrate due to transverse compression of the oxide during the hold period. Growth strains as low as $0.03 \%$ /cycle accelerate the rate of crack growth by more than a factor of $5 \times$ as the cracks grow beyond $30-40 \mu \mathrm{m}$ in length. The influence of the growth strains on the damage development rate, however, are less pronounced at $a=20 \mu \mathrm{m}$ and below. Comparing again with experimental results, for the $20 \mu \mathrm{m}$ crack length in Fig. 12, the predicted growth rate for growth strains of $0.03 \% /$ cycle is $12 \mathrm{~nm} /$ cycle; again this is within the range of rates observed experimentally. These results suggest that the model is capturing some of the essential details of the crack growth process in the early stages.

It is worth considering more deeply penetrating oxides, since cracks that pass through the bond coat and interdiffusion zone will subsequently be embedded in the superalloy substrate. Figure 13 shows the TGO penetration rate normalized by the oxide thickness into the superalloy for an initial crack depth of $200 \mu \mathrm{m}$, which is well beyond the combined $100 \mu \mathrm{m}$ thickness of the bond coat and IDZ. The predicted crack growth rate in Fig. 13 for $\Delta \varepsilon_{\mathrm{t}}=0.35 \%$ is approximately $25 \mathrm{~nm} /$ cycle, assuming 

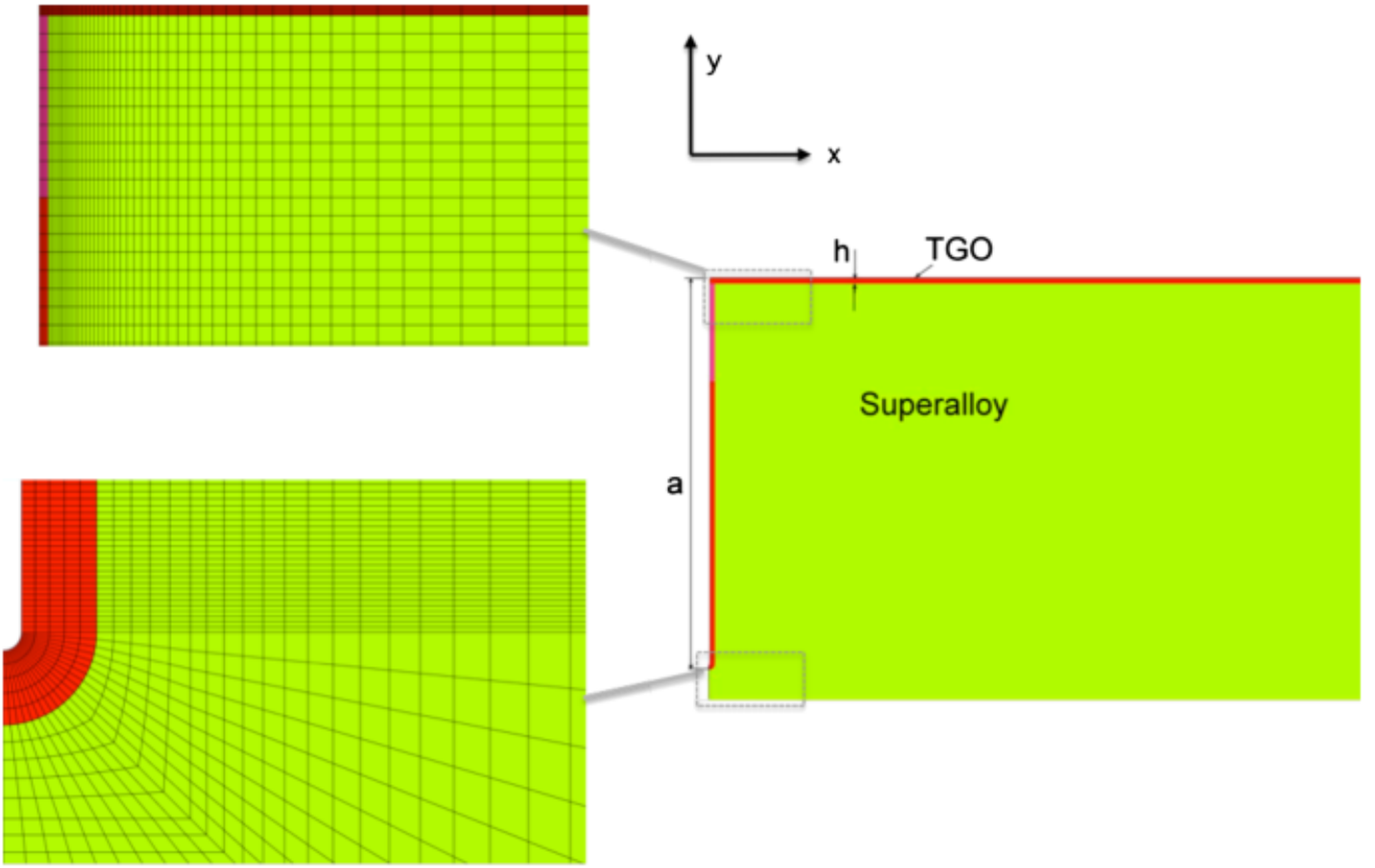

Fig. 9. Details of finite element mesh with oxide on surface and in crack tip.

a growth strain of $0.1 \%$ /cycle and bond coat and IDZ strengths of $50 \mathrm{MPa}$. In the interrupted tests on uncoated samples, a maximum crack depth of $200 \mu \mathrm{m}$ was reached at approximately $80 \%$ of life, Table I. At this point the crack growth rate was $\approx 150 \mathrm{~nm} /$ cycle. Earlier experimental measurements at $80 \%$ of life with a vapor phase aluminide-coated sample indicate a crack growth rate of about $40 \mathrm{~nm} /$ cycle at $80 \%$ life, ${ }^{6}$ so again the model predicts growth rates within a factor of 5 . It should be noted that the crack growth rate increases rapidly in the later stages of life, rising from $40 \mathrm{~nm} /$ cycle at $80 \%$ life to $200 \mathrm{~nm} /$ cycle at $95 \%$ of life, so comparison of experiments with the model is more challenging in the later stages of damage growth. Ultimately, as the crack penetrates deeply into the superalloy substrate, the rate of growth depends on the difference in the substrate and TGO strengths, Fig. 13(b).

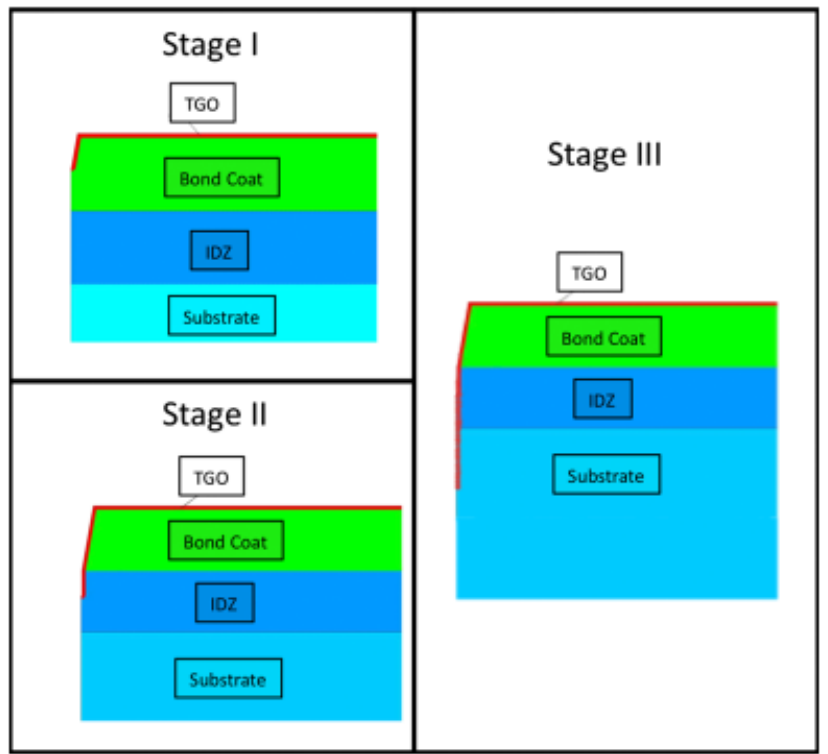

Fig. 10. Schematic of finite element models for the three stages of crack growth.
The formation of alumina along the crack faces by depletion of $\mathrm{Al}$ from the superalloy substrate can lead to a layer of soft $\gamma-\mathrm{Ni}$ adjacent to the oxide-filled crack. For this reason simulations were also conducted with soft layers surrounding the crack tip with thicknesses in the range of $1-3 \mu \mathrm{m}$ with growth strains ranging $0.02 \%-0.20 \%$. Decreasing the strength of the soft layer from 100 $\mathrm{MPa}$ (the same as the superalloy strength) to $10 \mathrm{MPa}$ accelerated the crack growth rate by an additional factor of $2-3 \times$.

\section{(2) Role of the Bond Coat and IDZ}

For the purposes of modeling the influence of coating and IDZ properties, the $\beta$-NiAl and interdiffusion zone are each considered to be $50 \mu \mathrm{m}$ in thickness with a $3-\mu \mathrm{m}$-thick TGO. The oxide penetration rate in each of the three stages has been addressed separately by generating a series of meshes for varying crack depths. The properties of the $\beta$-NiAl coating, IDZ, and superalloy substrate are varied along with oxide growth strains over bounds that might reasonably be expected in present and future systems, with bond coat and IDZ strengths varied parametrically from 10 to $100 \mathrm{MPa}$.

Figure 14 shows the influence of the bond coat strength on the TGO crack tip lengthening rate for Stage I growth with a crack depth of $20 \mu \mathrm{m}$ and a TGO thickness of $3 \mu \mathrm{m}$. At this early stage of the process where the cracks are shallow and the bond coat is softer than the substrate, the lengthening of the oxide causes not only penetration into the depth of the $\beta$-NiAl, but also a slight upward displacement of the bond coat surface of the order of $0.1 \mu \mathrm{m}$ in the " $y$ " direction, (direction indicated in Fig. 9). Determination of the overall crack growth rate in this early stage is complicated by the uplift as well as the included angle of the crack. Nevertheless, stronger bond coats do inhibit the rate of TGO lengthening as they increase in strength from 20 to $100 \mathrm{MPa}$. At this early stage in life, interdiffusion zone strengths have very limited influence on the overall response, Fig. 14, since the crack has not yet reached this zone. The overall crack growth rate within this stage for a bond coat strength close to $\beta-\mathrm{NiAl}$ is calculated to be about $4.1 \mathrm{~nm} /$ cycle, which is in reasonable agreement with the experimentally observed growth rate of $9 \mathrm{~nm} /$ cycle. $^{6}$ It is important to note that about half of the overall life is spent in Stage I, so strengthening the bond coat is likely to have an overall beneficial effect on SPLCF life. 
(a)

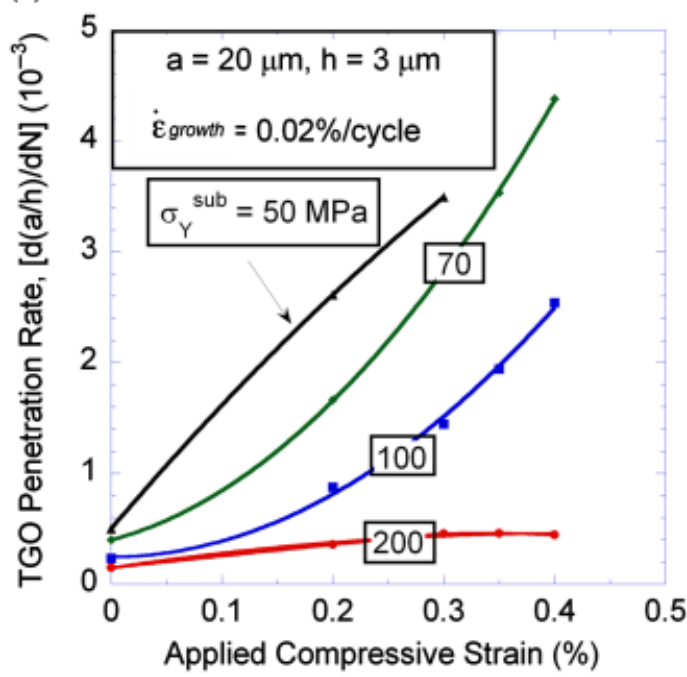

(b)

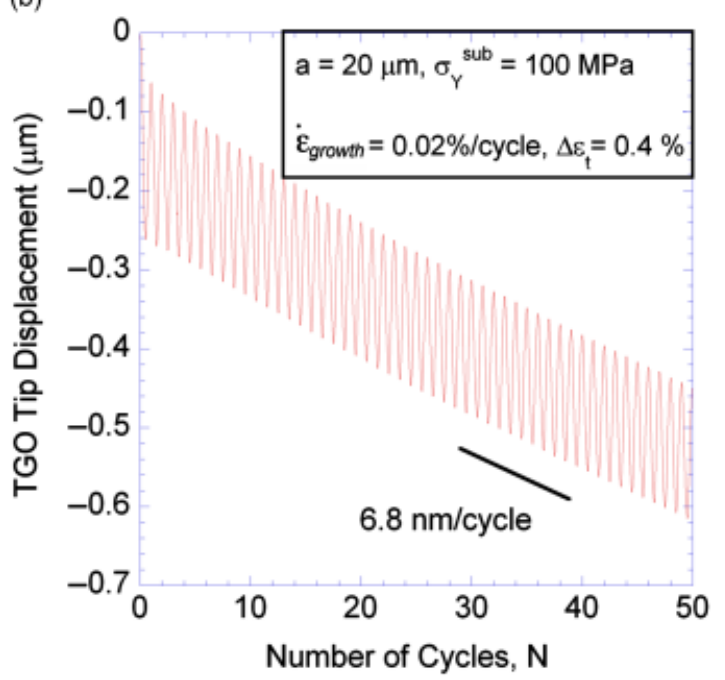

Fig. 11. (a) Influence of applied compressive strains on crack growth rates as a function of superalloy substrate strength and (b) cyclic displacement of the thermally grown oxide (TGO).

The crack tip extension rate in Stage II (crack depth of $70 \mu \mathrm{m}$, in IDZ) is shown in Fig. 15. A weak interdiffusion zone will clearly accelerate the rate of damage growth, particularly if the bond coat is weak (in this case with a strength less than approximately 60-70 MPa). Interestingly, even though the crack tip has progressed beyond the bond coat layer, the bond coat strength still influences the lengthening, since roughly half of the length of the oxide on the crack face is located along the bond coat layer. As both the bond coat and IDZ strengths approach that of the superalloy substrate, the TGO penetration rate is minimized. However, it is important to recall that bond coat and IDZ growth strains are likely different from those of the superalloy and higher growth strains or thicker oxides (more rapid oxidation kinetics) in the substrate could drive faster crack growth. Note in Fig. 16, that the TGO growth rate in Stage II is substantially enhanced by the fatigue cycling, particularly if the bond coat strength falls below $60 \mathrm{MPa}$. Also, as oxidation kinetics increase (the thickness of the TGO increases), the rate of damage growth increases. Finally, as Stage III is entered, the TGO extension rate is strongly influenced by the applied compressive strain in the fatigue cycle, Fig. 13, with crack extension rates increasing by more than a factor of 10 as the applied compressive strain increases from $0.2 \%$ to $0.8 \%$.

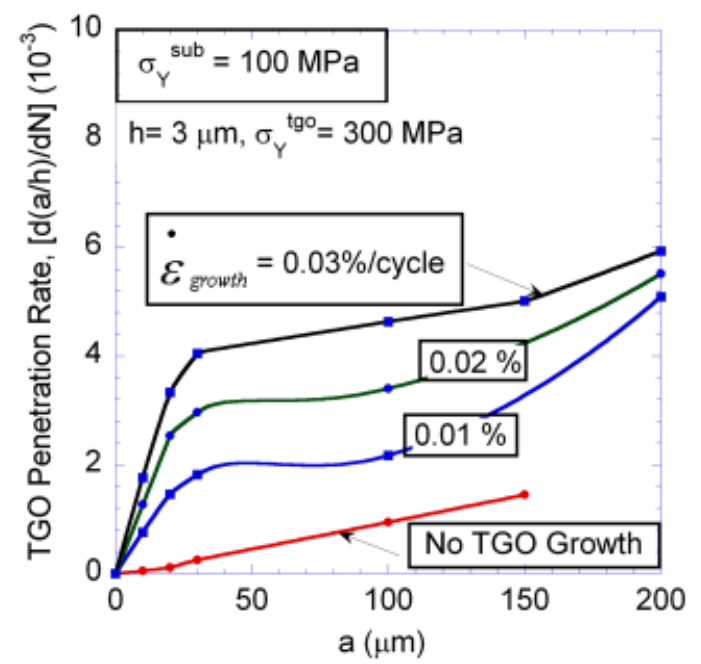

Fig. 12. Influence of oxide growth strains on crack growth rates at various crack depth.
As the crack progresses just beyond the IDZ, there is still an influence of the bond coat and interdiffusion zone properties, again because a substantial portion of the crack face is still located within these layers. There is a complex change in rates as the cracks extend from soft layers to harder layers and the reverse, Fig. 17. Apparently a soft interdiffusion layer is particularly detrimental to crack growth rates. Nevertheless, damage growth rates all converge to a common value as the crack progresses into the superalloy to a depth of $250-300 \mu \mathrm{m}$, which is 2.5-3 $\times$ deeper than the combined thickness of the bond coat and interdiffusion zone, Fig. 17. As the crack extends well past the bond coat and TGO, the rate of damage growth ultimately depends on the difference in strength of the TGO compared with the substrate and the bond coat and IDZ properties become less important, Fig 13(b). However, it should be recalled that only a small fraction of life $(<20 \%)$ is spent in these later "long crack" growth stages.

\section{Discussion}

Failure occurs during SPLCF cycling with compressive holds due to progressive growth of surface-initiated cracks containing a layer of alumina through the coating layers into the superalloy substrate. Finite element modeling demonstrates a fundamental role for growth stresses in the oxide and their relaxation and accommodation by creep in the bond coat, IDZ, and superalloy as a mechanism for propagating fatigue damage during SPLCF cycling. Growth strains during oxidation have been shown to develop due to counter-balanced outward fluxes of $\mathrm{Al}$ and inward fluxes of oxygen along grain boundaries during oxidation, permitting elongation of the oxide normal to the boundary in addition to oxide film thickening. ${ }^{19-21}$ This induces compressive stresses in the oxide that have been measured for oxides on several intermetallic coatings. ${ }^{25,26}$ Relaxation of these stresses during elevated temperature cycling ${ }^{22,27}$ is a key element of the "rumpling" process that occurs during cyclic oxidation, resulting in oxide spallation. ${ }^{21,22,24}$ During SPLCF cycling the role of the growth stresses is considerably more complex, since the oxide not only covers the surface of the sample, but penetrates deeply into the substrate with the assistance of the stresses induced by compressive fatigue loading and creep deformation that occurs during compressive holds. The creep deformation results in a net tension as the sample is returned to zero strain, permitting crack opening and further oxidation, Figs. 2 and 3. A complicating feature of the multilayered system is the fact that the growth strains or the kinetics of oxidation are likely to 
(a)

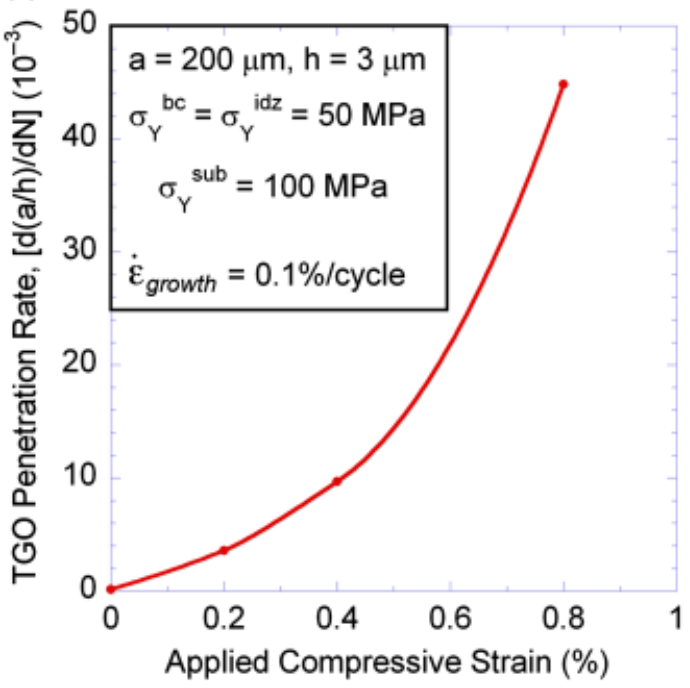

(b)

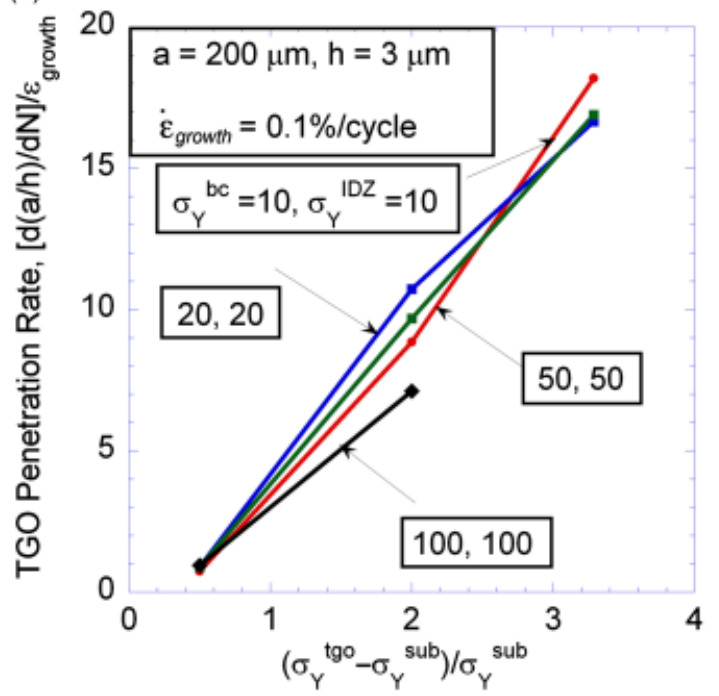

Fig. 13. (a) Rate of thermally grown oxide (TGO) penetration into the superalloy for an initial crack length of $200 \mu \mathrm{m}$ and (b) the role of substrate yield strength (b).

fluctuate in magnitude as the crack passes from the bond coat to interdiffusion zone into the substrate; indeed the model underestimates the rate of crack growth observed experimentally as the cracks penetrate into the superalloy to depths of the order of $200 \mu \mathrm{m}$, Fig. 13. Experimental studies of the development of growth stresses in oxides that form directly on the single crystal superalloys would clearly be useful.

Since the alumina has a high strength relative to the metallic coating layers and substrate in the temperature range investigated here, changes in the strength of the coating layers and substrate strongly influence crack lengthening rates. As the strength of the bond coat and IDZ approach the superalloy substrate strength, the rate of crack advance is substantially reduced, Fig. 15. Considering that approximately $80 \%$ of total SPLCF life is consumed in propagating cracks through the bond coat and IDZ, strengthening these layers should substantially improve SPLCF life. State of the art bond coats such as the Pt aluminide bond coat investigated here have strengths that are only $1 / 4-1 / 3$ of the superalloy substrate in the vicinity of $1000^{\circ} \mathrm{C}^{29,30}$ and the modeling suggests that these bond coats are soft enough to significantly assist damage growth in the coating in Stages I and II. The properties of the interdiffusion zone are relatively unexplored and likely to continue to evolve during high-temperature cycling

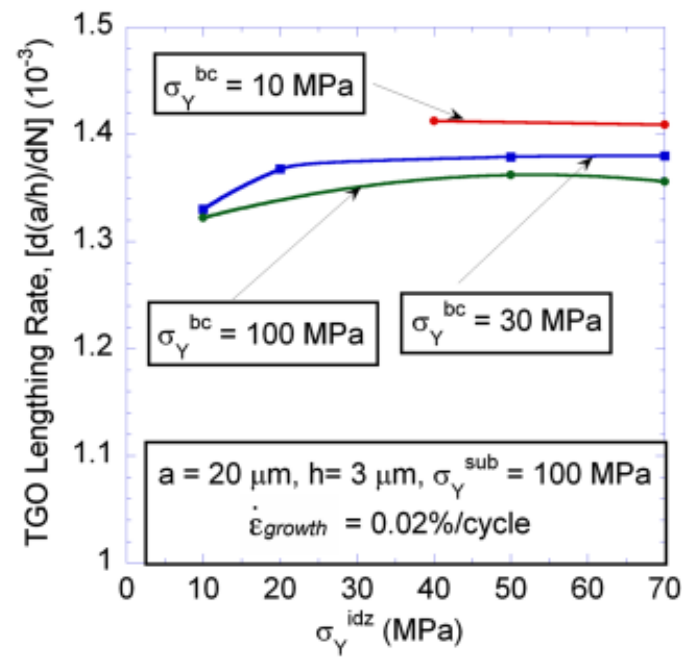

Fig. 14. Influence of bond coat and IDZ on Stage I crack extension rate. as the composition of this zone changes. More detailed measurements of IDZ properties and interdiffusion models that couple with property models would clearly be useful. An alternative approach would be to minimize the thickness or completely eliminate the IDZ zone by tailoring coating composition. Ultimately, a bond coating that would maximize SPLCF resistance would be comprised of a fine-scale two-phase system (for strengthening) that is in near-thermodynamic equilibrium with the superalloy and forms a slowly growing oxide with low growth stresses.

Modeling of the constituent layers demonstrates that damage growth rates all converge to a common value as the crack progresses to a depth that is $2.5-3 \times$ greater than the combined thickness of the bond coat and interdiffusion zone, Fig. 17, due to the fact that bond coat and IDZ influence the stress state in the crack face oxide for some distance after the crack tip moves beyond these layers. For the present system, the depth at which the bond coat and IDZ no longer influence the crack front processes, Fig. 17, is about $0.3 \mathrm{~mm}$, which in many airfoil designs could be equivalent to the entire wall thickness. ${ }^{4}$ This suggests that the properties of the oxide, coating, and IDZ may have an unexpectedly strong effect on airfoil life.

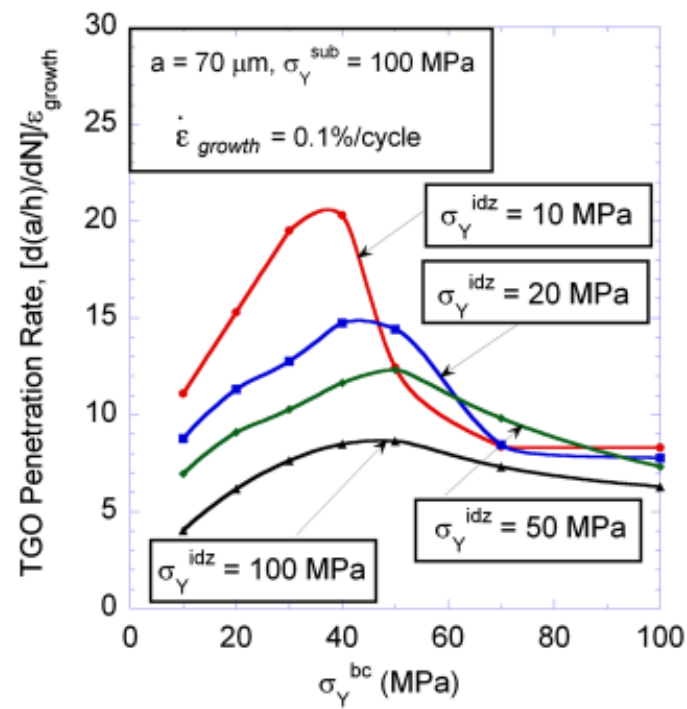

Fig. 15. Influence of bond coat and IDZ on Stage II crack extension rate. 


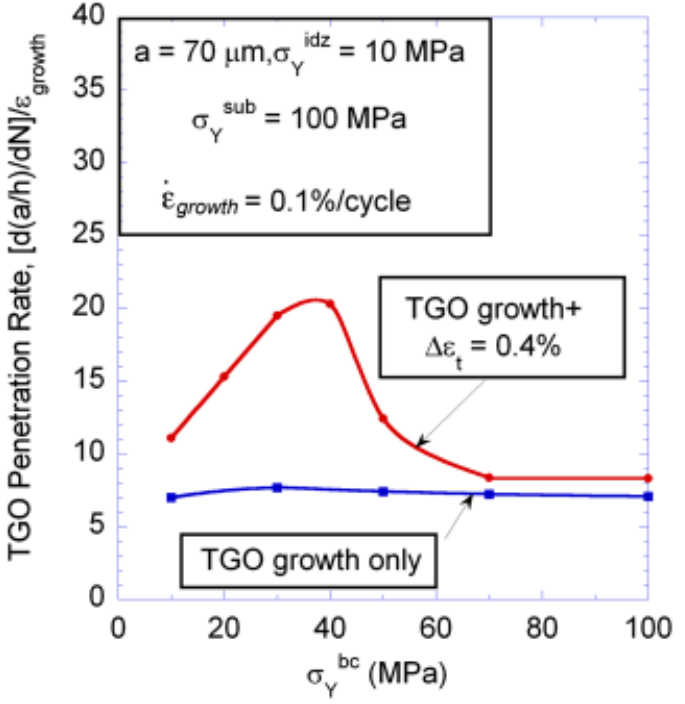

Fig. 16. Influence of fatigue cycling on crack growth through the interdiffusion zone in Stage II.

As the crack is well into Stage III growth, the crack growth rate, $\mathrm{d} a / \mathrm{d} N$, is dependent on the difference in the TGO-substrate strength such that, Fig. 13(b):

$$
\frac{\mathrm{d} a}{\mathrm{~d} N}=\lambda h \varepsilon_{\text {growth }}\left(\frac{\sigma_{\mathrm{y}}^{\mathrm{TGO}}-\sigma_{\mathrm{y}}^{\mathrm{Sub}}}{\sigma_{\mathrm{y}}^{\text {Sub }}}\right)
$$

where $\sigma_{\mathrm{y}}^{\mathrm{TGO}}$ and $\sigma_{\mathrm{y}}^{\mathrm{Sub}}$ are the yield strengths of the TGO and substrate at the test temperature, $h$ is the thickness of the oxide, $\varepsilon_{\text {growth }}$ is the oxide growth strain per cycle in the superalloy and a constant, ${ }^{18} \lambda \approx 4.5$ for the Rene N5 substrate. The crack is expected to grow at a steady rate until the threshold for macroscopic fatigue crack propagation is exceeded in the tension portion of the cycle, thereby entering Stage IV. For René N5 at $\Delta \varepsilon_{\mathrm{t}}=0.35 \%$, the maximum tensile stress is $190 \mathrm{MPa}$, Fig. 3 . Considering a typical long crack threshold of $\Delta K_{\mathrm{th}}=7$ $\mathrm{MPa} \cdot \mathrm{m}^{1 / 2}$, this transition would occur for a crack depth of $430 \mu \mathrm{m}$, in rough agreement with the crack angle transition observed in Fig. 7. Beyond this, rapid crack growth is expected, independent of coating properties. However, since this represents only a small fraction of overall SPLCF life, strategies for

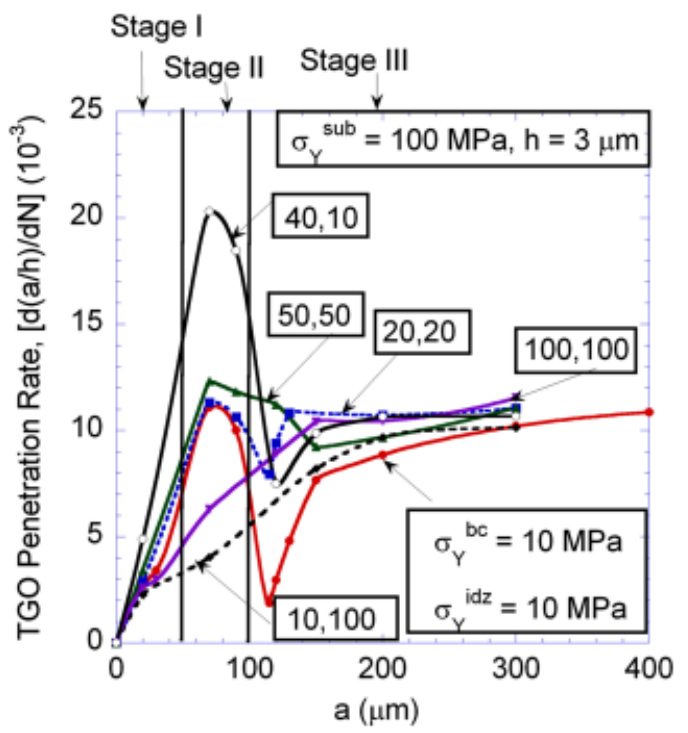

Fig. 17. Crack growth rates converge to a common rate after penetrating $250-300 \mu \mathrm{m}$ into the substrate. improving SPLCF resistance should focus on slowing the rate of damage growth during Stages I-III.

\section{Conclusions}

1. Failure due to fatigue cycling with compressive holds in single crystal samples with or without aluminide coatings occurs due to oxide-assisted crack growth from sample surfaces at $982^{\circ}$ and $1093^{\circ} \mathrm{C}$.

2. Oxide-filled cracks do not penetrate the bond coat and interdiffusion zone until approximately $80 \%$ of the cyclic life.

3. A model that accounts for relaxation of oxide growth stresses as the primary driving force for extension of the oxide through the coating and into the substrate provides reasonable predictions of the rate of crack growth through the bond coat, interdiffusion zone, and superalloy single crystal substrate.

4. The model predicts that cyclic life can be enhanced by strengthening of the bond coat and interdiffusion zone or by reduction of oxide growth stresses.

\section{Acknowledgments}

This paper is dedicated to the memory of Tony Evans, whose original insights to this problem motivated this research. The authors also acknowledge the support of the General Electric Company and useful discussions with D. Konitzer, J. Rigney, B. Hazel, and M. F. X. Gigliotti.

\section{References}

${ }^{1}$ A. G. Evans, D. R. Mumm, J. W. Hutchinson, G. H. Meier, and F. S. Pettit, "Mechanisms Controlling the Durability of Thermal Barrier Coatings," Prog. Mater. Sci., 46, 505-53 (2001)

${ }^{2}$ T. M. Pollock and S. Tin, "Nickel-Based Superalloys for Advanced Turbine Engines: Chemistry, Microstructure and Properties," AIAA J.: Propulsion Power, 22 [2] 361-74 (2006).

${ }^{3}$ A. G. Evans, D. R. Clarke, and C. G. Levi, "The Influence of Oxides on the Performance of Advanced Gas Turbines," J. Eur. Ceram. Soc., 28, 1405-919 (2008).

${ }^{4}$ Y. L. Bihan, P.-Y. Joubert, and D. Placko, "Wall Thickness Evaluation of Single-Crystal Hollow Blades by Eddy Current Sensor," NDT\&E Int., 34, 363-8 (2001).

${ }^{5}$ R. C. Reed, The Superalloys: Fundamentals and Applications. Cambridge University Press, Cambridge, 2006.

${ }^{6}$ A. Suzuki, M. F. X. Gigliotti, B. T. Hazel, D. G. Konitzer, and T. M. Pollock, "Crack Progression During Sustained Peak Low Cycle Fatigue in René N5," Metall. Mater. Trans., 41A, 948-56 (2010).

${ }^{7}$ A. G. Evans, M. Y. He, A. Suzuki, M. Gigliotti, B. Hazel, and T. M. Pollock, "The Mechanism Governing Sustained Peak Low Cycle Fatigue of Coated Superalloys," Acta Mater., 57, 2969-83 (2009).

${ }^{8}$ T. E. Strangman, "Thermal-Mechanical Fatigue Life Model for Coated Superalloy Turbine Components"; pp. 795-804 in Superalloys 1992, Edited by S. D. Antolovich., et al TMS, Warrendale, PA, 1992.

${ }^{9}$ J. W. Holmes and F. A. McClintock, "The Chemical and Mechanical Processes of Thermal Fatigue Degradation of an Aluminide Coating," Metall. Trans., 21A, 1209-22 (1990).

${ }^{10} \mathrm{P}$. Moretto and J. Bressers, "Thermomechanical Fatigue Degradation of a Nickel-Aluminide Coating on a Single Crystal Superalloy," J. Mater. Sci., 31, 4817-29 (1996).

${ }^{11}$ T. C. Totemeier and J. E. King, "Isothermal Fatigue of an Aluminide-Coated Single-Crystal Superalloy: Part II. Effects of Brittle Precracking," Metall. Mater. Trans., 27A, 353-61 (1996)

${ }^{12}$ J. S. Crompton and J. W. Martin, "Crack Growth in a Single Crystal Superalloy at Elevated Temperature," Metall. Trans., 15A, 1711-9 (1984).

${ }^{13}$ H. Zhou, H. Harada, Y. Ro, and I. Okada, "Investigations on the ThermoMechanical Fatigue of Two Ni-Based Single Crystal Superalloys," Mater. Sci. Eng., A, 161-7 (2005).

${ }^{14}$ N. Isobe and S. Sakurai, "Compressive Strain Hold Effect on High Temperature Low-Cycle Fatigue Crack Growth in Superalloys," Mater. Sci. Res. Int., 9, 29-33 (2003).

${ }^{15}$ R. Nutzl, E. Affeldt, and M. Goken, "Damage Evolution During Thermomechanical Fatigue of a Coated Monocrystalline Nickel-Base Superalloy," Intl. J. Fatigue, 30, 314-7 (2008).

${ }^{16}$ Y. H. Zhang, D. M. Knowles, and P. J. Withers, "Micromechanics of Failure of Aluminide Coated Single Crystal Ni Superalloy Under Thermomechanical Fatigue," Scr. Mater., 37, 815-20 (1997).

${ }^{17}$ E. Fluery and L. Remy, "Behavior of Nickel-Base Superalloy Single Crystals Under Thermomechanical Fatigue,” Metall. Mater. Trans., 25A, 99-109 (1994).

${ }^{18}$ M. Y. He and A. G. Evans, "A Model for Oxidation-Assisted Low Cycle Fatigue of Superalloys," Acta Mater., 58, 583-91 (2010).

${ }^{19}$ J. A. Nychka and D. R. Clarke, "Quantification of Aluminum Outward Diffusion During Oxidation of FeCrAlY Alloys," Oxidation Metals, 63 [5-6] 325-52 (2005) 
${ }^{20}$ V. K. Tolpygo and D. R. Clarke, "Microstructural Evidence for CounterDiffusion of Aluminum and Oxygen during the Growth of Alumina Scales," Mater. High Temp., 20, 261-71 (2003).

${ }^{21}$ V. K. Tolpygo and D. R. Clarke, "Oxidation-Induced Failure of BPVD Thermal Barrier Coatings," Surf. Coat. Tech., 146-147, 124-31 (2001).

${ }^{22}$ D. S. Balint and J. W. Hutchinson, "An Analytical Model of Rumpling in Thermal Barrier Coatings," J. Mech. Phys. Solids, 53, $949-73$ (2005).

${ }^{23}$ A. W. Davis and A. G. Evans, "Some Effects of Imperfection Geometry on the Cyclic Distortion of Thermally Grown Oxides," Oxidation Metals, 1573-4889 (2006).

${ }^{24}$ A. M. Karlsson, J. W. Hutchinson, and A. G. Evans, "A Fundamental Model of Cyclic Instabilities in Thermal Barrier Systems," J. Mech. Phys. Solids, 50, 1565-89 (2002).

${ }^{25}$ A. H. Heuer, A. Reddy, D. B. Hovis, B. Veal, A. Paulikas, A. Vlad, and M. Rühle, "The Effect of Surface Orientation on Oxidation-Induced Growth Strains in a Model NiCrAlY Bond Coat Alloy," Scr. Mater., 54, 1907-12 (2006).

${ }^{26}$ D. Hovis, L. Hu, A. Reddy, A. H. Heuer, A. P. Paulikas, and B. W. Veal, "InSitu Studies of TGO Growth Stresses and the Martensitic Transformation in the B2 Phase in Commercial Pt-Modified NiAl and NiCoCrAlY Bond Coat Alloys," Intl. J. Mater. Res., 98, 1209-13 (2007).
${ }^{27}$ B. W. Veal, A. P. Paulikas, B. Gleeson, and P. Y. Hou, "Creep in $\alpha-\mathrm{Al}_{2} \mathrm{O}_{3}$ Thermally Grown on $\beta-\mathrm{NiAl}$ and NiAlPt Alloys," Surf. Coat. Tech., 202, 608-12 (2007).

${ }^{28}$ B. Tryon, K. S. Murphy, C. G. Levi, J. Yang, and T. M. Pollock, "Hybrid Intermetallic Ru/Pt-modified Bond Coatings for Thermal Barrier Systems," Surf. Coat. Tech., 202, 349-61 (2007).

${ }^{29}$ T. M. Pollock and R. D. Field, "Dislocations and High Temperature Plastic Deformation of Superalloy Single Crystals"; pp. 547-618 in Dislocation in Solids, Vol 11, Edited by F. R. N. Nabarro, and M. S. Duesbery. Elsevier, Amsterdam, 2002.

${ }^{30}$ D. Pan, M. W. Chen, P. K. Wright, and K. J. Hemker, "Evolution of a Diffusion Aluminide Bond Coat for Thermal Barrier Coatings During Thermal Cycling," Acta Mater., 51, 2205-17 (2003).

${ }^{31}$ J. S. Van Sluytman, A. Suzuki, R. Helmik, A. Bolcavage, and T. M. Pollock, "Gamma Prime Morphology and Creep Properties of Nickel-Base Superalloys with Platinum Group Metal Additions"; pp. 499-507 in Superalloys 2008, Edited by R. C. Reed, K. A. Green, P. Caron, T. P. Gabb, M. G. Fahrmann, E. S. Huron, and S. R. Woodard TMS, Warrendale, PA, 2008.

${ }^{32}$ P. Y. Hou, A. P. Paulikas, and B. W. Veal, "Growth Strains in Thermally Grown $\mathrm{Al}_{2} \mathrm{O}_{3}$ Scales Studied Using Synchrotron Radiation," JOM, 61, 51-5 (2009). 